\title{
Senegalese Entrepreneurs in the USA and Managerial Decision making: A pilot study
}

\author{
Bassirou Tidjani*
}

\begin{abstract}
The paper looks at the conditions that influence how Senegalese entrepreneurs create and manage their businesses in the US while acquiring income in order to maintain and improve their social status in Senegal. The study uses the grounded theory to look at three cases in the city of Cincinnati. The study found that the creation of small businesses by Senegalese is the result of a process centred on the search for resources and the definition and protection of their business undertakings. This process is characterised by variations which depend on several conditions: owners' social profile, their management of the Senegalese community as a key stakeholder, their individual perception of the relation between religion and business, their personal understanding of the US reality, and their rejection or acceptance of the African system. This study concludes that Senegalese business owners approach doing business differently, even though they share the same basic culture and the same objective as their fellow migrants, which is to return home with an improved social status. However, given the methodology used (grounded theory), the sample and the pilot nature of the study, these conclusions cannot be generalised. The findings suggest that the study of immigrant businesses requires methodologies that are qualitative, interpretative and based on what business owners do and how they think.
\end{abstract}

* Ecole Superieure Polytechnique, Departement de Gestion, Université Cheikh Anta Diop, Dakar, Senegal. B.P. 5437, Dakar-Fann, Senegal. Email: btidjani@refer.sn. 


\section{Résumé}

L'article examine les conditions qui déterminent la manière dont les entrepreneurs sénégalais créent et gèrent leurs entreprises aux États-Unis dans un processus de stabilité et d'accumulation de biens qui aboutit à l'amélioration de leur statut social au Pays. C’est une étude pilote basée sur les exemples de trois personnes établies dans la ville de Cincinnati. La méthodologie utilisée est celle de la théorie reposant sur les faits.

L'étude a trouvé que la création de petites entreprises par les Sénégalais résulte d'un processus centré sur la recherche de profit, la définition et la sécurisation de leurs activités. Ce processus est caractérisé par des différences qui dépendent de plusieurs facteurs : le profil social de l'entrepreneur, ses interactions avec la communauté sénégalaise sur place, sa perception personnelle de la relation entre la religion et les affaires, sa propre compréhension de la réalité américaine et son rejet ou son acceptation du système africain.

En conclusion, l'étude montre que quand bien même les entrepreneurs sénégalais partagent la même culture de base et le même objectif qui est de retourner chez eux en vue d'améliorer leur statut social, et s'engagent dans un processus de réalisation de cet objectif, les voies empruntées sont différentes. Cependant, ces conclusions ne sauraient être généralisées compte tenu de la méthodologie utilisée (celle de la théorie à base empirique ou théorie reposant sur les faits) et du caractère réduit de l'échantillon de cette étude. Les conclusions suggèrent, pour étudier la pratique des affaires des immigrants, une méthodologie qui soit qualitative, interprétative et fondée sur ce que les entrepreneurs font et pensent.

\section{Introduction}

This study aims at understanding and explaining the emergence of Senegalese entrepreneurs in the USA. It is a pilot study of three case studies located in the city of Cincinnati, in the state of Ohio, which has witnessed an increased number of Senegalese habitants in recent years. As the Senegalese community grows, many Senegalese become involved in some business activities in an attempt on their part to reproduce the Senegalese society in the US. Consequently, various trades, skills and competencies emerge in order to respond to the needs of community members.

Generally, as citizens from a given country increase in number in a given area of a foreign country, they bring with them more trades, skills and competencies, try to reconstruct their home environment, and, thus, stimulate the creation of businesses whose mission is generally and primarily, at least at their inception, to respond to the needs of these citizens.

While Cincinnati media cites the number of Senegalese migrants as 2,000, informal accounts by Senegalese themselves suggest a population reaching at least 4,000 individuals. The majority of them are wage workers. But, 
many of them own small individual or family businesses in activities such as clothing, auto repairs, and food and general convenience stores.

In fact, the involvement of Senegalese in business activities abroad is not new. For many years, it has taken place in other countries in Africa, Europe, North America and more and more in Asia. However, while in the past it took the form of repeated trips by Senegalese traders to purchase items to be sold in Senegal or at most Senegalese migrants engaging in street vending in major foreign cities, today there are more formally established Senegaleseowned businesses abroad, including in the US.

There is no simple explanation to this phenomenon. Economic and social hardship in Senegal is probably an important reason but not a sufficient one because owning and managing a business successfully abroad requires, on the part of entrepreneurs, skills and resources of a particular nature. Similar issues are faced for example by Hispanic and Asian entrepreneurs in the US. However, while there has been a significant amount of research done on these communities, it is hard to find anything on African businesses despite the growing number of Africans in the US, and their greater involvement in independent economic activities. ${ }^{1}$ To the best of our knowledge, this is the first time that Senegalese businesses in the US are examined by researchers in the social sciences.

This study links managerial and social processes. Social processes include: coping with the Senegalese society and household needs back home while still living in the US; owners' relationships with the Senegalese community in the US; and integration in or isolation from the US society. Managerial processes include: searching for and managing financial, technical and human resources; identifying customer and labour markets; implicit or explicit strategies for prosperity designed by owners; and changes in these strategies.

In other words, we want to understand and explain the process by which a Senegalese man or woman decides to leave his or her home country with or without his or her family; to abandon a business in Senegal in many cases; to open a business in Cincinnati, or to first look for a factory job in order to generate start-up capital, or to swing between factory jobs and business ownership; and to have the return to his or her country as his or her main purpose, despite the fact that he or she can generate more wealth in the US than he or she would at home.

\section{Methodology}

Because some of the issues tackled in this research have been to some extent addressed in studies on immigrant businesses in the USA and in other countries, we had the choice between two approaches. First, we could apply 
existing frameworks to Senegalese businesses, based on the assumption that immigrants businesses follow the same pattern of creation, integration and development ${ }^{2}$ regardless of their owner's origins. Second, we could consider Senegalese people as a particular community with its uniqueness, thus requiring reliance on new concepts, categories and theories to explain entrepreneurship among them.

This research is based on the second approach for two reasons. First, we believe in Senegalese uniqueness on issues of entrepreneurship abroad. Taking Francophone Africa as a basis for comparison, empirical evidence shows that no other people from that area are as much involved in business activities in Cincinnati, and probably in the US in general, as Senegalese are. Second, studies on African businesses have generally suffered from the use by researchers of imported frameworks, concepts and theories.

In the present study, a business is considered to be any type of profit making activity, either manufacturing or service provision. These activities can be performed through street vending or in fixed-location structures, and are part of the 'ethnic economy' which consists of businesses 'owned and managed by immigrants as well as the co-ethnics they employ for wages and salaries' (Light 2004: 389). A Senegalese owner is defined as a person from Senegal (man or woman, regardless of his/her ethnicity, religion and social background) who decided, for reasons that may vary, to come to the USA and who is running a business, whether this was planned or not when leaving the home country. Thus, although the pilot study sample happens to be composed exclusively of individual men who already had a business in Senegal, future studies will probably include more diversity in the sample.

The methodology used is the grounded theory. It is recommended for the study of new phenomena and aims at the generation of new concepts, categories and theories. So far, there is no theory of the African firm, let alone a theory of African businesses abroad. The same is true of country-level studies; for example, there is no theory of the Senegalese firm. Attempts to construct a theory have been made through the study of the relationship (mostly the contradictions) between African cultures and modern management, but these attempts remain incomplete. ${ }^{3}$ Thus, given the newness of the study and its pilot nature, in order to minimise the influence of previous research and theories about immigrants and immigrant businesses in the US and in Europe, we first provide an analysis of the three Senegalese cases. Then, in the discussion section, we compare our findings to the findings of the most relevant existing literature.

In addition to the fact that we do not know of any study on Senegalese entrepreneurs in the USA, the choice of the grounded theory is based on an epistemological position. There are four possible epistemological options in 
social science research. First, positivism, mostly based on the deductive approach and rational thinking, tests empirical data on the basis of theories and hypotheses; here, individuals are seen as variables that can be objectively understood. Second, the participative approach combines rationalism and subjectivism: in this case, action is the basis for research because acting, being and knowing are seen as intertwined. Third, symbolic interactionism, ${ }^{4}$ based on an interpretative approach, is interested in the reality as perceived by people in their social interactions (ethnomethodology is close to this); for the researcher, reality is what people think of it and the meaning they give to what they do, not what others think or say about it. Fourth, structurationism brings in 'objective' structures de-emphasised by symbolic interactionism, and tries to provide a synthesis of positivism and interpretationism.

The lack of research on Senegalese businesses and on what determines their managerial choices in the US makes this study exploratory and led us to rely on grounded theory whose foundation is symbolic interactionism. This approach suggests de-emphasising at this stage of our research programme theories on Senegalese at home or abroad in general, or on Senegalese segmented on the basis of religion, ethnicity, geographical location, social status, political orientation, to cite but a few criteria, and to focus instead on the meaning given by individual Senegalese owners in the US to what they have been doing. This means that specific issues (such as religion, ethnicity, gender for example) are brought into the research only if raised by interviewees. ${ }^{5}$ The risk of this approach, inherent to the grounded theory, is to limit reality to what owners think. The advantage is the avoidance of biases and stereotypes due to an interpretation of owners' actions and discourse on the basis of existing theories.

As other approaches, the interpretative approach is not perfect. First, grounded theory takes into account theoretical sensitivity that 'refers to the personal quality of the researcher' (Strauss and Corbin 1990:41). The sources of theoretical sensitivity, namely, knowledge, professional and personal experiences, affect the researcher's awareness of the phenomenon under study. The researcher manages the impact of these sources by adopting an attitude of scepticism regarding previous knowledge and by following grounded theory research process (Strauss and Corbin 1990). Second, contrary to what positivism suggests, the researcher's subjectivity influences the research process, especially the data collected and their analysis.

So, to use the grounded theory means dealing with issues of reflexivity, relativism and interpretation. Ultimately, it is not about testing relationships among variables, but about the discovery of relevant categories and their relationships. Positivism tends to commit itself to particular methodological 
principles, theories and techniques. Reliability in methods and findings is indicative of validity; external validity (statistical generalisation) is a key issue. The grounded methodology, because it is grounded, is loyal to the meanings given by individuals to their actions and contexts (there is no right or wrong meaning). Its objective of understanding and explaining phenomena, and of discovering new concepts and theories, stimulates methodological openness. At this stage of our research programme, internal validity and analytical generalisation are given priority against external validity.

The three basic steps of the grounded theory are open coding, axial coding and selective coding. According to Strauss and Corbin (1990), ${ }^{6}$ the main purpose of open coding is to break down, examine, compare, conceptualise, and categorise data in order to identify concepts expressing what interviewees do and think. An analysis and synthesis of these concepts leads to the building of categories, sub-categories, properties and dimensions. ${ }^{7}$

Axial coding aims at making connections within and between categories by using the paradigm model. ${ }^{8}$ Selective coding is 'the process of selecting the core category, systematically relating it to other categories, validating those relationships, and filling in categories that need further refinement and development' (p. 116).

In practice, as seen later, these three steps are not sequential. Because data collection and analysis are performed simultaneously and based on a systematic comparison of concepts and categories, theory construction is present during the entire research process, although systematised at the selective coding stage. The strength of the method is its openness and almost unrestricted capacity to consider any information that may provide a better understanding of the phenomenon under study.

\section{The sample}

In grounded theory, sampling is theoretical, which, according to Strauss and Corbin (1990: 176), means 'sampling on the basis of concepts that have proven theoretical relevance to the evolving theory'. Theoretical sampling focuses on events and incidents, not persons per se. Therefore, it is the contribution of each case to the development of the theory that matters, not the number of cases.

This pilot study is based on three cases: those involved in an auto repair shop, a general store and a street vendor were interviewed. The choice of the auto repair shop was fortuitous and based on the owner's availability. His interview was considered informative enough to allow for the identification of concepts. Following principles of theoretical sampling, once concepts were identified, we looked purposefully for data reinforcing or contradicting 
these concepts. Thus, for the second interview several elements were given more emphasis or added. They were:

- Business and religion, because the first interviewee invoked the name of God many times in his discourse, but at the same time argued in favour of a total separation between his professional involvement and his religious life. This was so despite the fact that he was from a very religious family in Senegal. Also, he exclusively related the practice of retailing (buying and selling) among Senegalese to a particular religious group, the Mourids. ${ }^{9}$

- Business and the community resulted from our analysis of the first interview. Here it appeared that there was a contradiction between the first interviewee's reliance on the Senegalese community as his primary consumer market and his perception of this same community as an obstacle to the prosperity of his business. Jealousy among members of this community constituted the primary obstacle, according to him.

- Knowledge, skills and experience because the first interviewee presented them as the exclusive basis of his success and as a major asset in his relationship with the Senegalese community.

- Integration in the US society. The first interview considered that his illegal status greatly affected the way he was conducting his business.

To address these different issues, a general store was selected for the second interview. In the Senegalese community, the concept of 'general store' is defined as a business with a core activity (in the present case, selling African culture in the form of video tapes) and, in the same location, a variety of products (in the present case, clothes, sun-glasses, watches and any other item which met the needs of customers and generated money). The owner of this store was one of the leading members of an association regrouping Mourids in Cincinnati. Thus, community issues were among his primary concerns. This case was almost perfect to address issues raised by the first interviewee.

The third interviewee was a street vendor whose activities consisted in selling a large variety of items (clothing, perfume, cellular telephone cases, etc.). He was selected because we expected a different frame of mind and another way of doing things on his part given the nature of his business. This was confirmed especially on issues related to 'securing the business' and 'managing the community', discussed later. 


\section{Collection and analysis of data}

In the grounded theory, data collection and analysis are combined. Data were collected on the basis of an open-ended questionnaire with a content based on our own experience in the field of small businesses (i.e. theoretical sensitivity) and on informal discussions with Senegalese in Cincinnati. For each subject, we had at least two interviews in addition to several on-site observations. The decision to conduct several interviews made the length of each interview (60 to 90 minutes long) largely bearable for the owners who had busy schedules. Interviewees chose the day and time of each interview were. All interviews were recorded, entirely transcribed, then coded. ${ }^{10}$

After each interview we transcribed the recordings, performed open coding, corrected some mishandling and prepared for the following interview. To keep in touch with interviewees between two meetings or to clarify some data collected, telephone calls and on-site observations were made. This is the progressive and cumulative approach suggested in the grounded theory. So, instead of waiting for following interviews before executing open coding, concepts were identified on the basis of available data. These concepts were not considered as rigid and final, but just as a list of items that would be developed further quantitatively and/or qualitatively after each interview.

\section{Open Coding}

The analysis of data collected from the three interviews led to 17 concepts:

(i) gathering resources for the business;

(ii) social background;

(iii) searching for recognition;

(iv) nature of the business;

(v) market and the community;

(vi) integrating with the US society;

(vii) diversifying occupations;

(viii) entrepreneurship as a social status and a profession;

(ix) going home as the objective;

(x) positioning the trade through knowledge, skills and experience;

(xi) defining business performance;

(xii) business and the Senegalese community;

(xiii) lacking peace of mind and issues of insecurity;

(xiv) complying with the rules;

(xv) the process of entry into the US;

(xvi) religion and business;

(xvii) traditions and the African system. 
These concepts were then synthesised into eight categories:

(i) finding resources;

(ii) social profile;

(iii) defining the business;

(iv) reinforcing the African system;

(v) securing the business;

(vi) using the USA as a transition toward social improvement in Senegal;

(vii) linking religion and business;

(viii) managing the community as a key stakeholder.

For each category, subcategories were found and used for axial coding.

\section{Axial coding}

Axial coding led to the following table linking categories to subcategories based on the paradigm model. For each category, subcategories are labelled as cause, context, intervening variable, strategies, or consequence. ${ }^{11}$

The detailed analysis of categories on the basis of labelled subcategories allowed for:

- an understanding of the dynamics of each category;

- a definition of the relationship between categories, and

- subsequently, the positioning of each category in the process studied.

\section{Selective coding}

An analysis of the relationship among these eight categories led to the conclusion that 'Using USA as a transition toward social improvement in Senegal' was the core category. The other seven categories are the conditions (cause, context, intervening variable, and strategy) under which this main objective is achieved or not. To say that 'Using the USA as a transition...' is the core category means that the basic purpose of Senegalese entrepreneurs in the USA is to enter a process allowing them to accumulate wealth and to go back to Senegal to improve their households' social conditions and their social status. ${ }^{12}$

On that issue, our first contacts with Senegalese owners in the city of Cincinnati were revealing. All of them argued that, contrary to Asians and Hispanics entrepreneurs whose objective is to settle in the US, their goal was to leave as soon as possible. The same argument was put forth by the three owners interviewed during this pilot study. One of them even said, 'if I could reach my goal today, I would go back immediately ... This is not my country. I do not live here'.

So, the seven remaining categories represent the components of the process of accumulation experienced by Senegalese entrepreneurs. However, 


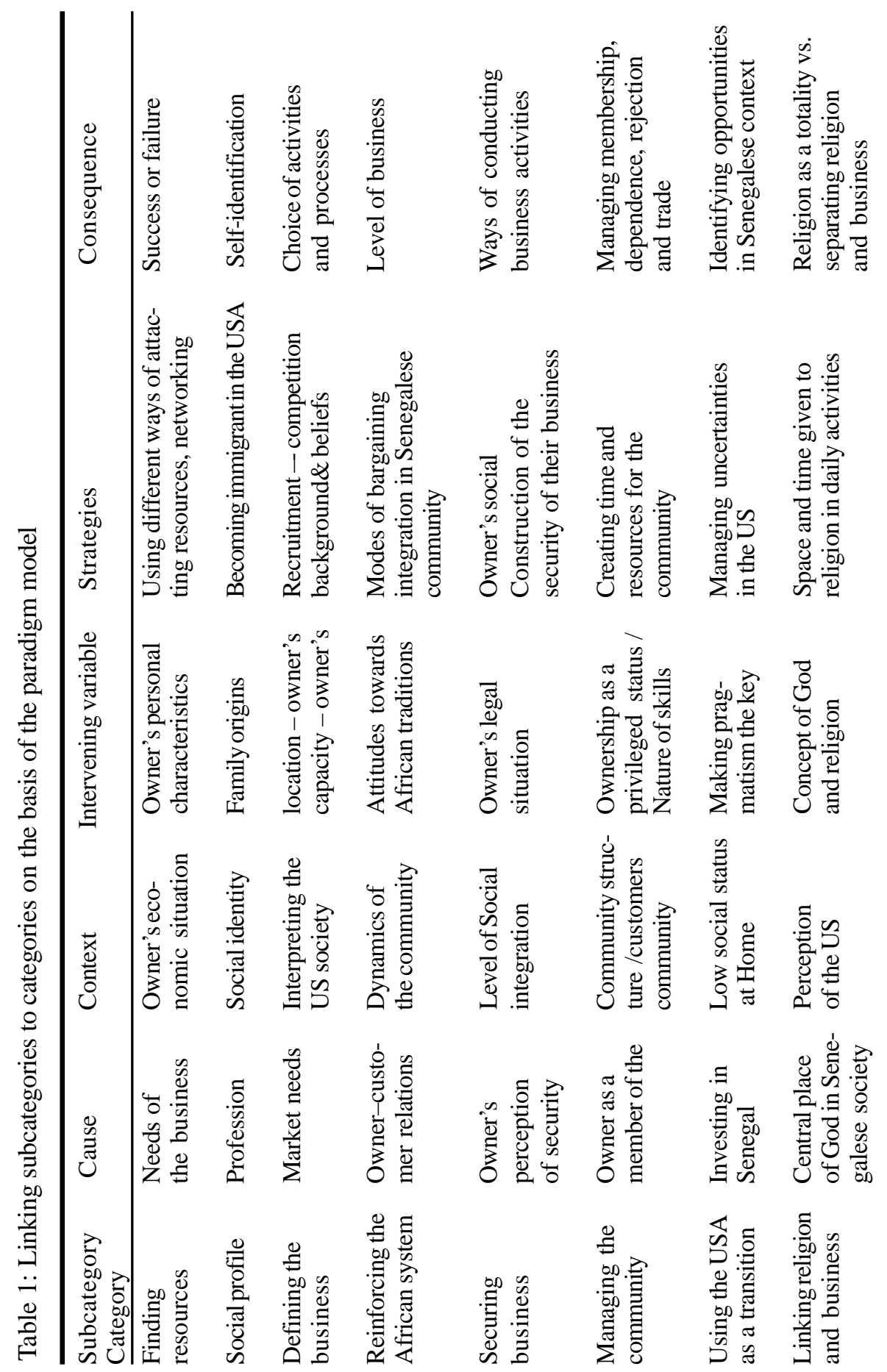


although these categories tend to be present in the experience of every Senegalese owner, their practical content was different from one owner to the other, as discussed hereafter.

An explanation of the above mentioned process and its variations is provided next.

\section{Explaining the process}

Expectations by Senegalese owners of a quick process of accumulation are based at the beginning on the perception of the US as a land of great opportunities. However, as the process unfolds, its complexity emerges. Its stabilisation takes longer because it appears to be related to complex interactions involving the owner and his or her objectives, the business, the family in Senegal, the US environment, and the Senegalese community in the US.

To explain this process is to look at the conditions influencing the ways Senegalese owners make managerial decisions in the USA, namely (i) the search for resources, (ii) the definition of their businesses, and (iii) the securing of their undertakings in order to stabilise a quick accumulation process leading to an improvement of their social status in Senegal. These are the three main elements of the process. ${ }^{13}$ (See figure 1 ).

Figure 1: The entrepreneurship process

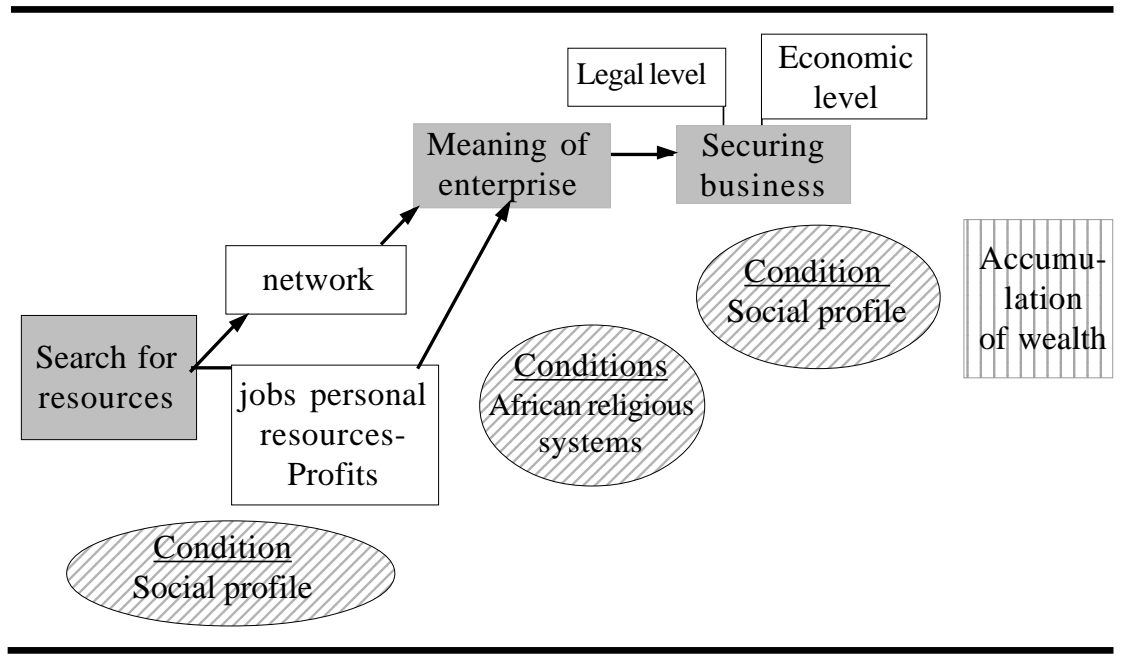

The first element is influenced by the owners' social profile, which includes their origins and social and professional experiences (i.e. biographies). The second element is influenced by their attitude towards the African system ${ }^{14}$ and their interpretation of the relationship between business and religion, 
both influencing their meaning of ownership. The last element is related to the way they manage the Senegalese community in the US, this community being both their support group (network) and their consumer market.

\section{The decision to migrate to the US and to own a business there}

Most Senegalese business owners in Cincinnati were already entrepreneurs in Senegal. The three entrepreneurs interviewed confirmed this pattern. For the general store owner, private ownership has been a family tradition. For all of them, the decision to come to the US resulted from business failure in Senegal. As they all put it, 'In Senegal, there is work but no money'.

Thus, coming to the US had for its purpose the accumulation of money as quickly as possible and to return in order to improve their social conditions. Information collected from people having an experience in the US, knowledge of success stories and their business experiences were the bases for Senegalese entrepreneurs' perception of the US as a land of opportunities.

\section{Finding resources}

The owners interviewed did not come to the USA with a starting capital. Thus, the search for resources was central to their success. Their social and professional profile was of a key importance in this search. The fact that they came to the US as illegal aliens prevented them from engaging in an established search process (banks or other financial institutions, government).

For the general store owner and the street vendor who came to the US through friends and relatives already established here, and on whom they relied at the beginning, networking was and remained afterwards their main strategy in their search for resources. Both of them were already involved in a network in Senegal. The nature of their business made a difference on this issue.

Comparing these two cases to the auto shop owner, it seems that the more marketable the skills required to operate the business are, the less owners will rely on networking, factory jobs and street activities for start-up resources. In such cases, owners will use profits generated by their activities to incrementally develop their businesses. Among the cases studied, while the general store's owner and the street vendor relied on networking, factory jobs and street vending in their search for start up resources, the auto shop's owner focused on his business cash flows. ${ }^{15}$

\section{Defining the business}

The way owners defined their businesses was an indication of their understanding of ownership. This understanding was largely influenced by the 
way owners interpreted the African system and understood the relationship between religion and business in the American context.

From the data analysis, two ways of defining a business appeared: the business as a community-oriented activity, and the business as an individual undertaking. In the first conception adopted by the general store's owner, being an entrepreneur leads to the construction of a social status to be perceived by others in the Senegalese community as synonymous with freedom and time to contribute to the betterment of this community. ${ }^{16}$ According to this owner, 'it gives you a lot of freedom and makes it easier to help others'. This contribution was viewed as an act of giving back to people who have participated in all aspects of the business, not just as customers.

The foundation of this interaction was the belief in the existence of a strong culture of solidarity in the Senegalese community. The transaction costs generated by this solidarity are not an issue, because the success or failure of any business depends on God's will. Thus, the conception of the business as a community-oriented undertaking was based on a strong belief in the African system and the non-separation between religion and business.

The fact that the general store owner relied on networking in his search for resources (finances, supplies, skills, and even space for his business) suggests a coherent relationship between the way he defined his business and the way he searched for resources. He stated several times that 'solidarity is what has allowed (him) to start (his) business in the US'.

The auto shop's owner instead viewed his business primarily as an individual undertaking, requiring the substitution of formal procedures (what he called 'the American way', i.e. a 'rationalisation of processes') for the African system perceived as 'backward', and the separation of work and religion. His hope was 'to work for Americans because they do not negotiate prices. They want to know if you are able to fix the car and when they can pick it up. That is their preoccupation. To the contrary, with Africans I do not make a lot of money'. In his conception, the Senegalese community was an obstacle to business profitability, not a space for solidarity and business success. This was coherent with the fact that in his search for resources, he did not rely on networking, but on the cash flows generated by his activities.

It appeared that the ways owners defined their businesses also had a great impact on how they secured them, as discussed next.

\section{Securing businesses}

Two factors made this issue central to the process of accumulation. The first was about legal issues and was related to the fact that the owners interviewed came to the US with a visitor's visa that made them illegal immigrants at the end of the visiting period. The second factor was economic and 
stemmed from the fact that the Senegalese community was perceived by owners as their primary space for recruiting, networking, and constructing their customer base, even in the cases where they regarded this community as an obstacle to business prosperity. Thus, securing the business involved two aspects: the legal stability of the business largely dependent on the legal status of the owner, and its economic viability essentially dependent on how owners managed the Senegalese community which included 80 to 95 percent of their customers.

Concerning the legal stability of businesses, although it was a greater concern for owners who were illegal aliens (cases of the auto shop owner and the street vendor) than it was for owners who had become 'legal' (the general store owner), it remained a preoccupation to all of them. The basis for that was the belief among Senegalese owners that the US was not their country and would never be. This meant for them that at any moment, they could be asked to leave, despite their recognition of the generosity of US laws allowing illegal immigrants to work or to run a business once they obtain a 'working permit'. As argued by one of them, 'if you are in a situation like the one I am in, you never know when you leave'.

As for the economic viability of businesses, because accumulation was the issue and because the Senegalese community was perceived by Senegalese owners as their customer base, managing the community was vital to the success of their businesses. For owners who possessed a communityoriented view, managing the community was a daily and quasi-natural preoccupation. For the auto shop owner who relied on an individualistic paradigm, it was compulsory for lack of a better market and required an efficient (in fact opportunistic) management of the paradox between integration in the Senegalese community and avoidance of an exclusive dependence of his business on this community.

This is how the owner of the car repair shop managed this paradox. According to him, 'if you try to use the American system, it will not work even though it is better, and you will not be able to socialize and do business with them (i.e. the Senegalese community). They may begin to discover wrong things about you. Unfortunately, these wrong things, although untrue, will be known to and believed by the entire Senegalese community'.

For this owner, there was the belief that in the long run the Senegalese community would not be the only or most important consumer market available to him. Therefore, he viewed the community primarily as an instrument for business prosperity but only for a period of time. So, in all cases, at least in the short run, the Senegalese community, given its position as quasi-ex- 
clusive customer, was an unavoidable stakeholder for Senegalese entrepreneurs.

Among owners adopting a community-oriented approach, the case of the street vendor whose activities, because of their nature did not target the Senegalese community, is worth mentioning. For him, this community was just a component of his consumer market (his customers were mostly US natives), but a vital network for different types of resources (information, especially legal; financial support in hard times; supplies; socialisation; religion, to cite but a few examples).

\section{Accumulation as a consequence of the process}

At the time of the interview, the car repair shop owner, who had followed an individualistic paradigm, and had been in the USA for less than five years, had stabilised a relatively efficient accumulation process and had largely invested in Senegal (construction of a three-storey building for let), thus partly realising the purpose of his coming to the US, even before returning. The possibility of investing in Senegal whilst still in the US brought a new dimension in his accumulation process, namely the prospect of a professional base in both the US and Senegal. As a consequence, the necessity to acquire a legal status progressively took a central place in his life.

For the general store's owner and the street vendor who adopted a community-oriented approach, managing the community seemed to involve transaction costs that may have negatively affected business performances and slowed down their accumulation process. They had been in the US for more than twelve years without their families and were still relying on survival strategies for themselves and their households in Senegal.

\section{Discussion}

At the time of this research, only one of the three owners had succeeded in somehow stabilising a quick accumulation process. But, even in his case, this success was not strong enough to make him ready to return to his home country. However, all of them were contributing to an improvement of their households' material conditions by regularly sending money to senegal.

This is a critical point because sending money to senegal slows down the accumulation process and extends owners' stay in the US. As explained by one owner, 'when we live in the US, our expenses double. They include us. Plus, we continue to provide for the household in Senegal; we pay a rent there. The rent paid for the location of the business here in the US is higher than what we would have paid at home. Thus, we may generate higher profits here, but our expenses are also higher'. Immigrant entrepreneurs who do not have the return to home as their main objective, such as Asians 
(Waldinger and Aldrich 1990), do not support such costs because they try to bring their families into the US as quickly as possible.

As long as going back to Senegal remains the main objective, household expenses in Senegal are considered by Senegalese owners as a compulsory cost (these expenses may even increase given the development of the household in size over the years). The consequence is that the accumulation process will depend on the capacity of owners to extend their business or to improve the quality of their management in order to increase their profits.

The data show that Senegalese owners emphasise business extension at the expense of an improvement of managerial processes. None of the owners perceived for example the necessity of a basic accounting system allowing for a better management of their activities, let alone of a marketing of their services in order to build a wider customer base. They relied on an implicit niche strategy aiming at responding to the needs of the Senegalese community, even in the case of the auto shop owner.

So, less than a year after the completion of our interviews, two of the owners were considering an extension of their activities. The auto repair shop's owner was looking for a larger space. The general store's owner in fact acquired a much spacious location in a different community and added the selling of foodstuff to his business. The street vendor was considering looking for a factory job, then going back home to visit his family, and coming back to restart his business with a new orientation and the support of friends and family.

The case of the general store's owner is worth discussing because he realised his extension project while the auto shop owner was just considering it. First, his move to a new community dominated by African-Americans took him out of the spaces where the Senegalese community was concentrated (although he remained easily reachable) and brought some changes in his customer base, which nevertheless remained largely Senegalese. Second, interestingly, to reinforce his community and religious orientation, he established his business in a building in which were also located the mosque and the Koranic school run by the religious association (Mourid) that he led. In addition to this extension, he became involved in a part-time job. This shows how the central objective of quick accumulation led in his case to diversified but unrelated occupations in which the only common denominator was the generation of money.

Third, this extension did not lead at all to an improvement of managerial processes. This goes against the traditional logic of business growth but is coherent with the owner's objective. In effect, expectations for a quick accumulation process laid the ground for a reliance on precarious and rudimentary business processes and techniques on his part. In his mind, there 
was no need to be involved in the use of sophisticated (and eventually costly) managerial tools if the objective was to return home as soon as possible.

This particular case shows that although it is true that ethnic 'neighborhoods may be the starting point of ethnic businesses...', the dynamics of their evolution does not always result from changes in the structure and habits of these neighbourhoods (Waldinger, McEvoy, \& Aldrich 1990). In the case of the general store owner, at least three factors played a role. They were the possibilities offered by the environment (here, possibilities to find a new location for the business) ${ }^{17}$ combined with managerial constraints (here, the search for better financial performance) and the need by the owner to reinforce his religious and community orientations (the nonseparation between his business, religion, and the Senegalese community).

Generally, issues of ethnic neighbourhoods are introduced in the debate on immigrant businesses because of their economic advantages, namely, affordable housing, labour force proximity, or the existence of a natural customer base (Waldinger, McEvoy \& Aldrich 1990). The cultural (especially the entrepreneurial culture) and psychological reasons why business owners choose to remain attached or even dependent on a particular community (not always their community) are not sufficiently addressed.

The case of the auto repair shop owner who at the time of the interview was doing relatively well, performance-wise, allows for a discussion of such issues. This owner lived in an African-American dominated community where he also had his shop. However, most of his customers who were from the Senegalese community, lived in other neighbourhoods.

Thus, the prosperity of his business depended more on the Senegalese community which also constituted his space of socialisation, than it did on his direct neighbours. Therefore, what made his business ethnic was neither the nature of the service provided (auto repairs), nor his dependence on his neighbourhood as a customer base, but the fact that for the time being the Senegalese community was his niche market, although his hope was to do business with a larger public including Americans.

Several elements of his discourse allow for an understanding and explanation of his choices. First and already mentioned, he did not consider that solidarity was present in the Senegalese community, and was convinced that the future of his business was in the larger American market. Second, despite his critique of the Senegalese community in Cincinnati, he did not intend to ignore it culturally. Finally, security was a central aspect of his undertaking given his illegal status. This last point deserves more detailed explanation.

Given the non-negligible number of Senegalese with an illegal status, to be in an environment dominated by them was to be avoided. This owner 
understood very well that business works better when it occurs in an environment that is secure both economically and legally, that the security of his business could not be separated from his own security and that legal problems related to his status would automatically affect the survival of his activities.

In order to face this issue he constructed an understanding of his situation in the US context and consequently adopted a social and professional behaviour of which the main elements were the following, in addition to staying in an African-American dominated neighbourhood. First, he acknowledged his illegal and fragile status. ${ }^{18}$ Second, he was convinced that he had been monitored by the US police and was known as an illegal immigrant. ${ }^{19}$ Third, he was also convinced that through good social and professional behaviour, he would be able to live and practice his trade in Cincinnati with no trouble. ${ }^{20}$ Issues of security were also very central to the street vendor who was an illegal immigrant but less central to the general store owner who had become a legal resident a few years ago.

The central outcomes of this study are the following. First, although all Senegalese owners interviewed, whose main objective was to accumulate wealth and to go back Home, faced issues related to finding resources, defining and securing their businesses, they resolved them differently. Why is that?

Studies on ethnic businesses tend to focus on shared beliefs and behaviours (general picture data) ${ }^{21}$ and to ignore individual differences within particular immigrant communities. ${ }^{22}$ From a sociological viewpoint, it allows for broad comparative analyses of immigrant groups. However, we are not convinced that it provides a detailed realistic picture of the dynamics of individual businesses in particular sectors, an equally key issue.

In effect, given the fact that immigrant businesses are private and most of the time individual or family-owned, although it is important to be able to compare Cubans, South Koreans and Chinese for example, it is as relevant to understand the strategic choices made by individual owners within each group. ${ }^{23}$ In fact, understanding individual choices may contribute to better comparisons by allowing the specification of conditions and changes in the evolution of businesses. But this is also a methodological issue.

In this pilot study, we used the grounded theory that allowed us not only to identify a general process, but also to show that the different components of this process were emphasised differently by Senegalese owners based on their trades, skills, beliefs, legal status, managerial constraints, origins, understanding of their situation and levels of success or failure experienced, among others. For example, studies on immigrant businesses generally argue that reliance on social and financial resources through networking in the 
owner's community at the initial stage is central and explains greater successes among Koreans, Cubans and Chinese compared to African Americans and Mexicans (Raijman and Tienda 2003).

Although we acknowledge evidence supporting this argument, our data show that of the three Senegalese owners studied, one (the auto shop owner) deliberately chose to rely on his resources through systematic reinvestment of the cash flow generated. Also, the general store owner moved quicker than the auto repair shop owner toward the development of his business, because he had more managerial constraints. Instead, the auto repair man (as well as the street vendor) focused more on the security of his business because he was an illegal immigrant and had a particular interpretation of the relationship between the success of his business and his legal status.

Putz (2002) makes an important contribution to the debate on the relationship between communities and the individual on issues of immigrant entrepreneurship. ${ }^{24}$ His argument begins with a critique of traditional research on ethnic businesses, based on opportunities and resources approaches, whose main conclusion is to explain successes or failures among immigrant businesses by the possession or absence of 'specific cultural resources'.

According to Putz, opportunity approaches lead to patterns of interpretation where the actions of entrepreneurs are presented as 'responses to structures which are beyond their direct influence', while a resources approach leads to the belief of the existence of 'homogeneous communities' of which entrepreneurs are part. He argues that because the entrepreneur is an 'individual human agent' permanently involved in a specific decision making process with specific goals, studies on immigrant businesses ought to be more 'qualitative, interpretative and action-oriented'.

Putz's arguments are similar to Granovetter's critique of classical sociology's oversocialisation in the study of economic action (1985). According to Granoveter, oversocialisation leads to mechanical conceptions of how society influences individual behaviour. Instead, he believes that individuals are involved in purposive actions and that these actions are 'embedded in concrete, ongoing systems of social relations' (p. 487). ${ }^{25}$

The cases of Senegalese owners show that although they originated from the same culture, as a shared symbolic order, and had the same initial objective of a quick accumulation process, they developed different strategies. Furthermore, the data on the trajectory of each owner clearly show that along the years, these strategies have not been deliberate but emerging ones, built into the accumulation process and based on a trial and error approach.

Thus, culture as a general and inclusive category, is not sufficient to explain what they have done. An understanding of how, in practice, individual entrepreneurs constructed their own space of action that may lead to 
the reinforcement, reshaping or rejection of some aspects or all aspects of their original symbolic order, is also needed. This does not exclude shared views on some issues and possibilities for collective action.

The decisions made by the general store owner to relocate his store, to diversify his services and to take a part-time job, and by the auto repair owner to focus on the construction of his own secure environment, resulted from a practical interpretation (susceptible of changes) of their original culture and their social reality in the US, knowing that they needed to be involved in actions leading to a quick accumulation of wealth. Thus, opportunities and resources (and constraints as a matter of fact) do not exist independently of individual owners' interpretations of their situations. In other words, entrepreneurs belonging to the same community may perceive different opportunities, resources and constraints under particular conditions.

Thus, beyond the identification of general categories that Senegalese owners are concerned with, namely, finding resources, defining the business and securing it, what also matters is an understanding and an explanation of the scheme of interpretation of each owner on the basis of his actions. But, in all cases, there was mixed embededdness, i.e., the entrepreneurs' positioning in the US was influenced both by their socio-ethnic environment and the American market and institutional environment. ${ }^{26}$

The second most important outcome of this study is that there may not be a 'one best way' or 'best practice' on how to become a successful immigrant entrepreneur. Inter-ethnic comparisons of immigrant businesses are useful. But, they ought to be seen more as studies allowing to better understand what different ethnic communities do on issues of business creation and management than recipes or norms for success.

The study of Portes (1987) shows not only how much processes of business creation and management among Cubans are different from other ethnic groups' processes, but also how different these processes are within the Cuban community itself based on social classes, periods of immigration, and individual capacities, for example. Because most research on immigrant businesses aims at finding a general theory of success or failure, some complexities specific to each community are left out.

When African American (or black) businesses are compared to Asian businesses, we have explanations on why the latter are more successful but we have few explanations if any, about successful African American businesses (Waldinger and Aldrich 1990; Lee 1999; Uneke 1996). Research such as Krogstad's (2004) study on the entrepreneurship of a Chinese family over two generations stands out.

These arguments further justify our choice of a methodology that does not rely totally on existing theories to understand and explain Senegalese 
businesses in Cincinnati. The relevance of a detailed analysis of patterns of settlement for an understanding of immigrant businesses (Portes 1987) suggests caution about the applicability of existing theories (generally based on the study of Jews, African Americans, Asians, Cubans and Mexicans), to Senegalese and other African businesses.

Senegalese patterns of settlements present characteristics that do not exist or are not apparent among other immigrants. ${ }^{27}$ First, a significant number of Senegalese entrepreneurs in the US remain illegal for some time, in some cases for a long period of time. Second, the persistence of relatively strong ethnic identities in Senegal leads to the creation of ethnic enclaves in the US that differ from the homogeneity of other immigrant groups. ${ }^{28}$ Whether or not this influences Senegalese businesses' operations (capital, networking, strategies, labour and consumer markets, performance, to cite a few) in the US needs to be investigated in future studies.

\section{Conclusion}

At this point can we formulate a theory of entrepreneurship specific to Senegalese owners? Probably not, for two reasons: First, this is a pilot study. Despite the fact that it is based on detailed data and comparisons, it is not possible to generalise the findings. Second and most important, we expected a high level of homogeneity in the practices of Senegalese owners; instead, we discovered diversity. More investigations are thus required. Future studies ought to combine several elements. First, given frequent changes introduced in their practices, there is a need to follow the evolution of the three pilot cases over a few years. Second, the sample size needs to be increased on the basis of theoretical sampling. Cities like Cleveland and Columbus, in Ohio, which also have a large Senegalese population (maybe even larger than in Cincinnati), will be progressively included. Third, given the emergence of Senegalese women owners in the community, gender issues need to be addressed.

As mentioned earlier, grounded theory is about dealing with issues of reflexivity, relativism and interpretation. As a result, we wanted to report in a rather descriptive fashion, understand and explain as much and as accurately as possible what Senegalese businesses in Cincinnati are about, based on individual entrepreneurs' own accounts of what they do and on our interpretation of these accounts and observations of what they do.

\section{Notes}

1. For example: on Cubans, see Wilson and Portes (1980); on Mexicans, see Raijman and Tienda (2003); for group comparisons including Asians and others, see Waldinger, Aldrich and Ward (1990), Lee (1999), Waters (1999). 
2. This is to a large extent the conclusion reached by Boissevain et al., (1990) in their study of 'Ethnic entrepreneurs and Ethnic strategies'.

3. See Kamdem 2000; Nkakleu 2001; Tidjani 1995a, 1995b; Norderhaven and Tidjani 2001.

4. See Mead 1934; Blumer 1969; Charon 2001.

5. In the present study for example, religion was brought into the debate by the first interviewee and was then included in the questionnaire. Ethnicity, to the contrary, was never invoked by interviewees and was thus seen as a non-issue.

6. See also, Strauss, A. (1987).

7. Properties are 'attributes or characteristics pertaining to a category'; dimensions are 'location of properties along a continuum'; dimensionalising is 'the process of breaking a property down into its dimensions' (p.61).

8. The paradigm model allows one to determine which sub-categories is a cause, a contextual variable, an intervening variable, a strategy or a consequence (see Strauss and Corbin: 96).

9. The name 'Mourids' designates a particular Muslim brotherhood group in Senegal where there exist two other important groups: the Tidjanes (the most important in number) and the Layenes (the third largest group). Of all the three groups, the Mourids have by far the best organisational capacities both in Senegal and abroad. Cincinnati is a case in point.

10. The auto shop owner was interviewed three times in his apartment after his working hours. Despite the fact that the shop was closed, he received phone calls from his customers. As a mechanic, he had to be available to his customers, and many of these customers have become his friends. Thus, as it happens in Senegal within the auto repair sector, quasi-permanent availability is an important competitive factor. This relationship is part of what the auto shop owner qualified as ‘the African system' because these phone calls were about negotiating over issues (mostly prices and deadlines) outside regular working hours. The general store owner was interviewed two times in his store. Compared to interviews with the auto shop owner which were more relaxed despite phone calls, those conducted in the store carried some tensions because the owner was dealing with customers at the same time. But, this was positive because it allowed one to combine interviews, on site observation and discussions over observed issues (bargaining, concessions made by the owner, etc). The street vendor was interviewed three times in my office, on campus. The second interview lasted only 30 minutes for professional reasons. During this research, on site observation was not scheduled. We could visit the different sites at any time. We visited each site at least three times (more for the street vendor).

11. Properties and dimensions are not presented in this table for space reasons.

12. This core category contradicts 'making it' arguments stating that '...certain immigrant groups establish themselves in the American economy and move up within it’ (Bonacich 1987: 446). 
13. These three main elements are drawn from the seven categories. The four remaining are defined as conditions of the process.

14. The African system is defined as the systematic bargaining over prices and/or deadlines for payment by customers. This is based on the assumption by customers that businesses will always overprice their products or services in order to maximise their profits. This led businesses to overprice their products and services knowing that customers will always bargain. Actually, it is not clear which of the two attitudes is the cause and which is the consequence. The African system is an interactive process that originates from buying and selling traditions in Senegal, and in most of Africa.

15. This finding supports Marger's findings in his study of immigrant entrepreneurs who went to Canada through the Canadian Business Immigration Program (2001). He argues that high levels of human capital among immigrant entrepreneurs foster disconnectedness from ethnic communities and social capital.

16. The positioning of entrepreneurs in a high or privileged social status in the Senegalese community resembles the conclusion of Wilson and Portes (1980) that Cuban entrepreneurs (identified as enclave workers) in a number of ways are part of the primary labour market not the peripheral (secondary) one in the US.

17. This looks like what Kloosterman and Rath (2001) and Waldinger, Aldrich and Ward (1990) characterised as the opportunity structure.

18. He stated the following: 'This is a foreign country. It does not belong to us...'

19. Quote: 'I am sure that they know that there is an African working here ... Pictures of me were taken. They went to all the stores where I buy my parts. When I started the shop, they came from time to time. They would come here, wait and leave once I opened the shop.'

20. His statement was: 'I was given the location of the shop, and I believe that if this was dangerous I would not have had it. This is what gave me the courage to continue. It seems that once they [the Police] realise that nothing wrong was going on there, they stopped bothering me. In general, I only take small repair work in my shop. I refuse to take big works, risky ones because I do not want to disturb the neighborhood. Everything that I do is declared and I pay all my taxes every three months'.

21. This often leads to labour market or resource disadvantage theories. For a review and comparison of these theories (see Uneke 1996; Waters 1999).

22. In her study of African American, Jewish and Korean entrepreneurs, based on a co-ethnic advantage and disadvantage approach, Lee (1999) examines within ethnic group differences. But, it is about internal competition due to the concentration (followed by saturation) of a particular ethnic group in a specific economic activity. Thus, this is more about conflict than strategy.

23. We define strategic choices as choices that have a significant impact on the main objectives of the business. 
24. In her study of the Wong family, Krogstad (2004) comes close to Putz's approach when she suggests a focus on the entrepreneur and on how s/he obtains markets and makes profits. But, later in her study she seems to emphasise the need for a comparison between ethnic groups.

25. For concrete examples of how social structures affect economic actions, see also Portes and Sensenbrenner (1993).

26. On the concept of mixed embeddednes, see Kloosterman and Rath (2001) and Rath and Kloosterman (2000).

27. These characteristics are present among many other African immigrants; they will be given more consideration in future studies.

28. Here, the concept of 'ethnicity' is not equivalent to nationality as understood in studies on immigrant businesses. It is indicative of sub-groups within a particular nationality. In the city of Cincinnati, three ethnic enclaves can be identified within the Senegalese community: the Toucouleur, the Wolof and the Sarakole enclaves. They are all Senegalese, but belong to separate ethnic groups who live in different geographical locations in Cincinnati.

\section{References}

Blumer, Herbert, 1986, Symbolic Interactionism Perspective and Method, Berkeley: University of California Press.

Boissevain, Jeremy, et al., 1990, ‘Ethnic Entrepreneurs and Ethnic Strategies’, in R. Waldinger, H. Aldrich and R. Ward (eds) Ethnic Entrepreneurs Immigrant Business in Industrial Societies, London: Sage Publications, pp. 131-156.

Bonacich, Edna, 1987, 'Making It in America: A Social Evaluation of the Ethics of Immigrant Entrepreneurship’, Sociological Perspectives, Vol.30, 4,(Oct.): 446-466.

Charon, M., 2001, Symbolic Interactionism An Introduction, An Interpretation, An Integration, Seventh edition, Prentice Hall.

Granovetter, Mark, 1985, 'Economic Action and Social Structure: The Problem of Embeddedness', The American Journal of Sociology, Vol.91, 3, (Nov.): 481-510.

Kamdem, Emmanuel, 2002, Management et Interculturalité en Afrique Expérience camerounaise, Les Presses de l’Université Laval, l’Harmattan.

Kloosterman, Robert and Jan Rath, 2001, 'Immigrant Entrepreneurs in Advanced Economies: Mixed Embeddedness Further Explored', Journal of Ethnic and Migration Studies, Vol.27, 2, (April): 189-201.

Krogstad, Anne, 2004, 'From Chop Suey to Sushi, Champagne, and VIP Lounge', Social Analysis, Vol.48, 1, (Spring): 196-217.

Light, Ivan, 2004, Immigration and Ethnic Economies in Giant Cities. Paris: UNESCO.

Lee, Jennifer, 1999, 'Retail Niche Domination among African American, Jewish, and Korean Entrepreneurs’, American Behavioral Scientist, Vol.42, 9, (June/ July): 1398-1416.

Marger, Martin N., 2001, 'The Use of Social and Human Capital among Canadian Business Immigrants', Journal of Ethnic and Migration Studies, Vol.27, 3, (July): 439-453. 
Mead, H. George, 1934, Mind, Self and Society from the Standpoint of a Social Behaviorist, Chicago: The University of Chicago Press.

Nkakleu, Raphael, 2001, 'Pour une approche contingente des PME au Cameroun. Contribution à la connaissance de l'identité des dirigeants et des modes de gestion du potentiel'. Thèse de Doctorat en Sciences de Gestion, Université Louis Pasteur, Strasbourg Beta.

Norderhaven, Niels and Tidjani, Bassirou, 2001, 'Culture, Governance, and Economic Performance. An explorative study with a special focus on Africa', International Journal of Cross Cultural Management, Vol. 1, No. 1.

Portes, Alejandro and Sensenbrenner, Julia, 1993, 'Embeddedness and Immigration: Notes on the Social Determinants of Economic Action', The American Journal of Sociology, Vol. 98, 6, (May): 1320-1350.

Portes, Alejandro, 1987, 'The Social Origins of the Cuban Enclave Economy of Miami', Sociological Perspectives, Vol.30, 4, (Oct.): 340-372.

Putz, Robert, 2002, 'Culture and Entrepreneurship - Remarks on Transculturality as Practice', Tijdschrift voor Economische en Sociale Geografie, Vol.94, 5: 554-563.

Raijman, Rebecca and Tienda, Marta, 2003, 'Ethnic Foundations of Economic Transactions: Mexican and Korean Immigrant Entrepreneurs in Chicago’, Ethnic and Racial Studies, Vol.26, 5, (Sep.): 783-801.

Rath, Jan and Kloosterman, Robert, 2000, 'Outsiders’ Business: A Critical Review of Research on Immigrant Entrepreneurship’, The International Migration Review, Vol.34, 3 (Fall): 657-681.

Strauss, Anselm and Corbin, Juliet, 1990, Basics of Qualitative Research: Grounded Theory Procedures and Techniques, Newbury Park, California: Sage Publications.

Strauss, Anselm, 1987, Qualitative Analysis for Social Scientists, New York: Cambridge University Press.

Tidjani, Bassirou, 1995a, 'Management et Cultures Africaines: une problématique, plusieurs approches. Vers la construction d'une typologie', Revue de Gestion des Ressources Humaines, N²17, Nov., pp. 25-35.

Tidjani, Bassirou, 1995b, 'Approche Socio-culturelle de l'entreprise au Sénégal', Africa Development/Afrique et Développement. Vol. XX, №3, pp. 89-104.

Uneke, Okori, 1996, 'Ethnicity and Small Business Ownership: Contrasts between Blacks and Chinese in Toronto', Work, Employment and Society, Vol.10, 3, (Sep.): 529-548.

Waldinger, Roger and Aldrich, Howard, 1990, 'Trends in Ethnic Business in the United States', in R. Waldinger, H. Aldrich and R. Ward (eds) Ethnic Entrepreneurs Immigrant Business in Industrial Societies, . Sage Publications. pp. 49-78.

Waldinger, Roger, et al., 1990, 'Opportunities, Group Characteristics, and Strategies’, in R. Waldinger, H. Aldrich and R. Ward (eds) Ethnic Entrepreneurs Immigrant Business in Industrial Societies, Ashgate: Sage Publications. pp. 13-48

Waldinger, Roger et al., 1990, 'Spatial Dimensions of Opportunity Structures', in R. Waldinger, H. Aldrich and R. Ward (eds) Ethnic Entrepreneurs Immigrant Business in Industrial Societies, Ashgate: Sage Publications pp. 106-130. 